\title{
Health MDG's: what was been achieved in improving maternal and child health
}

\author{
Flavia Bustreo ${ }^{7}$
}

In 2000, world leaders agreed on the eight Millennium Development Goals (MDGs) — which range from halving extreme poverty to halting the spread of HIV/AIDS, reducing maternal and child mortality and providing universal primary education. MDG 4 called for reducing the under-five mortality rate by two thirds between 1990 and 2015, and MDG 5 set the ambitious targets of reducing the maternal mortality ratio by three quarters during the same period and achieving universal access to reproductive health.

As we reach the end of the MDG period it is time to take stock of what has been achieved, what are the lessons learned and what are the future directions.

\section{Where are we now?}

Substantial progress has been made. The number of under-five deaths worldwide has declined from 12.7 million in 1990 to 5.9 million in 2015 (1). With regard to maternal health, there were an estimated 289000 maternal deaths globally in 2013, a decline of 45\% from 1990 (2).

Many factors and initiatives have contributed to progress. The UN Secretary General's initiative, "Every Woman, Every Child", based on the Global Strategy for Women's and Children's Health launched in 2010, has become one of the fastest growing movements in health, attracting over 400 commitments by 300 partners together with US\$ 60 billion in financing (3). Furthermore, several regional initiatives and renewed strategies have helped translate the global targets and strategies into action at the country level. The "Saving the lives of mothers and children: rising to the challenge", initiative in the Eastern Mediterranean Region is a notable example of this.

Yet, despite these substantial gains, it is important to note that the progress is insufficient to achieve the MDG 4 and 5 targets and progress has not been even within and between countries. While some countries have made tremendous progress and reached the MDGs, other countries have experienced setbacks and slower progress. Humanitarian crises, fragile settings and disease outbreaks have been contributing factors to this. The situation in the Eastern Mediterranean Region reflects this picture. Some countries, such as Egypt, have reached the MDG 4 by a reduction in under-five mortality from 86/1000 live births (LB) in 1990 to $24 / 1000$ LB in 2015, whereas underfive mortality reduction in other countries, such as Somalia, has been far less and levels remain very high [180/1000 LB 1990 to $137 / 1000$ LB in 2015 (4)]. As a region, maternal mortality halved between 1990 and 2013 and the risk of dying from pregnancy-related cause is now $1 / 180$, close to the global average of $(1 / 190)$. But regional averages mask differences between countries. Afghanistan dramatically reduced maternal mortality (1200 maternal deaths/100 000 LB 1990 to 400 maternal deaths/100 000 LB in 2013) but the risk of dying from pregnancyrelated causes is $1 / 49$, more than three times higher than the regional average. Like Afghanistan, other high burden countries in the Region have had more moderate reductions and are not likely to achieve MDG 5.

Within countries, equity analysis has shown consistent pro-rich and pro-urban inequalities for all the main maternal and child health indicators, except for exclusive breastfeeding (3). Although equity is frequently discussed, it is seldom prioritized and systematically measured in policies and programmes. We have also learned that multisectoral action is key for achieving results. An analysis has suggested that as much as $50 \%$ of the reduction in under-five child mortality across 142 countries is due to factors outside the health sector, such as education, access to clean water and sanitation, and women's participation in politics (5).

\section{Where are we going?}

Building on the success and lessons learned of the 2010 Global Strategy, the Global Strategy for Women's, Children's and Adolescents' Health, 2016-2030 was launched in September this year after an extensive consultation process involving governments, civil society, the private sector, UN agencies and other constituencies. With ambitious yet achievable targets and fully aligned with the Sustainable Development Goals (SDGs), the 2016-2030 Global Strategy offers a roadmap to end all preventable deaths of women, children and adolescents, and ensure that they not only survive, but also thrive and transform the societies they live in. The updated Strategy's inclusion of adolescents, emphasis on multisectoral 
action, gender, equity and rights, and focus on humanitarian and fragile settings among others, pose new challenges to all stakeholders and partners on how to translate the targets and objectives into action at country level.

In this context, it is important to consider the health of women, children and adolescents as an investment that will bring enormous benefits. The Global Strategy points out that increased and sustained financing over the next 15 years would yield at least a 10-fold return on investments from social and economic gains. Reaching the goals of the Global Strategy requires increased financing, and particularly domestic financing. The launch of the
Global Financing Facility, a financing partnership that brings together, under national leadership and ownership, a range of key stakeholders to provide smart, scaled and sustainable financing for reproductive, maternal, newborn, child and adolescent health, is a step in that direction. Overall, it is important to align and increase funding in support of countries' prioritized plans, with the aim of closing the existing financing gap and achieving the broad goal of universal health coverage.

The Global Strategy and its operational framework will be presented to the World Health Assembly in May 2016 and WHO is committed to work with countries and partners to transform the bold ideas of the Strategy into reality. In the Eastern Mediterranean Region, the "Saving the lives of mothers and children: rising to the challenge" initiative supported 9 high burden countries in accelerating progress towards MDGs 4 and 5 which provides a basis on which to build the actions to operationalize the goals of the Global Strategy. It will be important to keep this momentum and to support the countries in updating and implementing their strategies and plans in line with the SDG targets for 2030 and the Global Strategy for Women's, Children's and Adolescents' Health.

Let us all work together to make it happen.

\section{References}

1. UNICEF, WHO, The World Bank, United Nations Population Division. Levels \& trends in child mortality. Report 2015. Estimates developed by the UN Inter-agency Group for Child Mortality Estimation. New York: United Nations Children's Fund; 2015.

2. WHO, UNICEF, UNFPA, The World Bank, United Nations Population Division. Trends in Maternal Mortality: 1990 to 2013. Estimates by WHO, UNICEF, UNFPA, The World Bank and the United Nations Population Division. Geneva: World Health Organization; 2014

3. Every woman, every child, every adolescent: achievements and prospects: the final report of the independent Expert Re- view Group on Information and Accountability for Women's and Children's Health. Geneva: World Health Organization; 2015.

4. Global Health Observatory data. Geneva: World Health Organization; 2015 (http://apps.who.int/gho/data/node.main. MATMORT?lang=en, accessed 4 November 2015).

5. Kuruvilla S, Schweitzer J, Bishai D, Chowdhury S, Caramani D, Frost L, et al. \& on behalf of the Success Factors for Women's and Children's Health study groups. Success factors for reducing maternal and child mortality. Bull World Health Organ. 2014 Jul 1;92(7):533-44B. doi: 10.2471/BLT.14.138131. PMID: 25110379 